\title{
PHONETIC DATA AND PHONOLOGICAL ANALYSES
}

\section{J.C. ROUX}

This paper is basically concerned with the relationship between phonetic data and phonological analyses. ${ }^{1)}$ It will be shown that phonological analyses based on unverified phonetic data tend to accommodate ad hoc, unmotivated, and even phonetically implausible phonological rules. On the other hand, it will be demonstrated that a phonological analysis (of the same phenomenon), based on verified phonetic data, accounts for these data in an acceptable, natural and credible manner. Examples will be taken from the phenomenon of labialization in Sesotho ${ }^{2)}$ to illustrate the point that it is absolutely necessary to make a clearcut distinction between "data" and "facts" in generative phonological descriptions.

Attention will first be given to different types of phonetic data: impressionistic phonetic data of Tucker (1929) and of Kunene (1961) will be discussed, after which some experimental phonetic data on the phenomenon of labialization in Sesotho will be presented. A phonological analysis of Ponelis (1974) based on unverified phonetic data will then be examined, after which finally, a phonological analysis based on verified data will be considered.

\section{Phonetic data}

On two occasions Sara Garnes (1973 : 273; 1974 : 144) makes the following statement: "In abstract phonology phonetic facts are frequently taken for granted and verification of the phonetic facts is largely ignored." This seems to be quite true of many, if not of most of contemporary phonological descriptions. Very seldom are scientific methods adopted to check the correctness of phonetic data on which phonological analyses are eventually based. Or, seen from another angle, very seldom are the phonetic outputs predicted by the phonological theory, checked to determine whether they actually occur in the language. Eighteen years ago Ladefoged (1960: 387), in referring to the value of phonetic statements, basically made the same point in stating "It is odd that linguists, who pride themselves on the rigour and scientific nature of many of their concepts should nevertheless be so tolerant of vague unverified statements in their field." 
Botfia (in preparation : 82$)^{3}$ ) explicitly points out that generative grammarians tend to use the expressions "datum/a" and "fact(s)" in a loose and synonomous manner, ${ }^{4}$ and he then suggests that a definite distinction should be made between "facts" and "data":

(1) "A DATUM is a fragment of information, which has not been thoroughly tested on the basis of some criterion of correctness. A FACT, on the other hand, is a fragment of information of which the accuracy, after careful testing, seems to be beyond reasonable doubt. In short, a fact represents what, in all probability, is actually the case. It is a tested and probably correct datum about reality." (ibid.)

As it is not the function of linguistic theory to. provide "criteria of correctness" in order to distinguish between "non-facts". and "facts", these criteria obviously may be sought in other disciplines. Experimental phonetics as well. as pschycolinguistic testing may, for instance, play an important role in dis* tinguising between the "non-facts" and the "facts" of a corpus of phonetic data.

It need, however, always to be remembered that not all phonetic "facts", are necessarilly linguistically relevant, and furthermore, that the linguist has no a priori measure at his disposal in order to distinguish between linguistically relevant facts, or linguistically irrelevant facts (cf. Botha 1971 : 101). Botha (1971 : 100) nevertheless points out that the linguist may receive ".... a certain measure of guidance from the general theory of phonology" to assist him in making just such a distinction.

The following relationship therefore seems to exist between "data" and "facts":

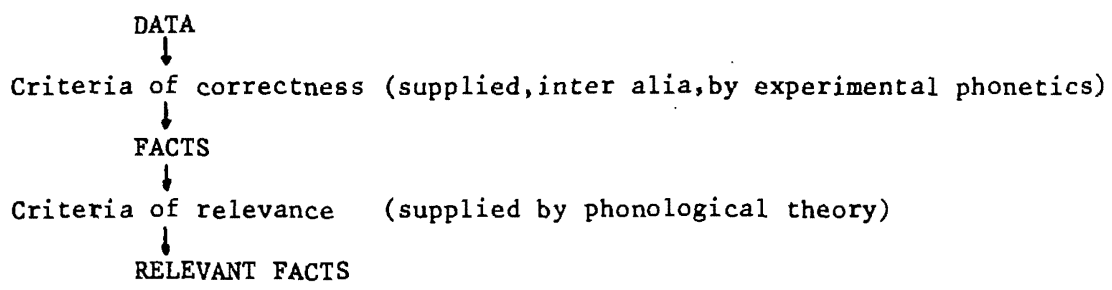

Consider now the phenomenon of labialization in Sesotho. In this language there are at least two different phonetic descriptions of this phenomenon. These two descriptions are both impressionistic in nature, and represent respectively, the views of

(i) a trained phonetician - Tucker (1929), and

(ii) a phonetically trained native speaker - Kunene (1961). 
Traditionally, the views of Tucker are accepted as being the "correct" views of the phenomenon. On the other hand, no serious attention has ever been given to the views of Kunene. While phonological descriptions are of ten based on the data presented by Tucker (1929), 5) it need nevertheless be pointed out that no principled reason has ever been presented for either

(i) accepting the views of Tucker, or

(ii) rejecting the views of Kunene.

Although the views of Tucker and of Kunene are very much the same on various points, they nevertheless seem to differ on at least one crucial point, i.e. on the segmental status of a labialized articulation. These two views will now be explicated separately.

\subsection{The impressionistic phonetic data of Tucker}

The main views of Tucker (1929) on the topic of labialization in Sotho are the following:

1. "The labialized consonant is in short precisely the consonant one hears before a back vowe1" (1929: 74);

2. "Labialized consonants, (...), are identical in articulation with the consonants found before back vowels" (1929: 76);

3. "... the lips (and the back of the tongue where possible) take up the $w$ position during the formation of the consonant itself (...) - so that the w-element persists throughout the articulation of the sound, and is not a separate succeeding semi-vowel, ...." (1929: 74);

4. "In the case of aspiration, $(\ldots$.$) , what we hear is a la-$ bialized sound aspirated rather than an aspirated sound labialized." (ibid.);

5. "I think we should here have recourse to digraphs, suffixing the symbol $w$ to the sounds labialized. It is, however, to be understood that each digraph represents a single sound of double articulation, not a sequence of sounds ending in w." (ibid.).

6. ".... in a word like setjwana, if the explosive element is pronounced ejectively, i.e. with simultaneous glottal closure, the word should be transcribed setjw'ana (not sets'wana), as the unrounding of the lips accompanies the release of the oral closure, while glottal release follows both." (ibid.).

In terms of these views the following phonetic transcriptions may be presented: 


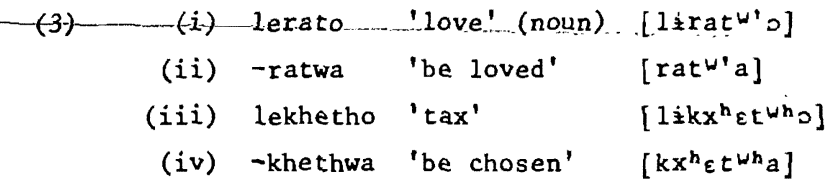

The main points therefore to be made are:

(i) A consonant articulated before a back vowel, and a consonant articulated before a semivowel /w/ are both labialized:

$$
\begin{array}{lll}
/ C_{0} / & : & {\left[C w_{0}\right]} \\
/ C w a / & : & {\left[C w_{a}\right]}
\end{array}
$$

(ii) There is no separate succeeding semivocalic segment:

$$
\text { /Cwa/ : [Cwa] and not [ } \mathrm{CWwa}^{\mathrm{w}}
$$

(iii) following from (ii), aspiration/ejection 'follows' labialization:

$$
\begin{aligned}
& / C^{\prime w a} \\
& / C^{h} w a /: \\
& \left.\left[C^{\prime} a\right] \text { and not [ } C^{\prime} w a\right]
\end{aligned}
$$

\subsection{The impressionistic phonetic views of Kunene}

Kunene (1961) has the following views on the phenomenon of labialization in Sesotho:

1. "When a consonant other than a labial consonant is imediately followed by the labio-velar semivowel $\mathrm{w}$, the latter imparts labial characteristics, in the form of lip-rounding, to the preceding consonant." (1961: 118);

2. ".... the lips are fully rounded for the w before the other articulating organs take up the position/s for the articulation of the preceding consonant or consonant combination. In other words, there is anticipation of the w-element ..." (1961:111);

3. "... the w-element precedes, persists through, and follows the articulation of the labialized consonant. Before the consonant there is a silent $w$, while after the consonant there is an audible w." (19 $\overline{6} 1$ : 120 Kunene's emphasis : J.C.R.).

4. "This means that where w occurs after a consonant, we have, contrary to the opinion of Tucker and others, a sequence of two sounds, viz. a labialized consonant or consonant or consonant combination $+w$." (ibid. Kunene's emphasis : J.C.R.).

5. "The interval between the consonant and the following w is (...) long enough in Sotho for the sequence to be regarded as a combination." (ibid.) 
The main point, therefore, made by Kunene is that a consonant is labialized by a following /w/, and that the semivowe 1 exists as a phonetic segment after the labialized consonant. Thus,

$$
\text { lowal : [Cwa] }
$$

The differences between the views of Tucker and of Kunene seem to be quite clear. In view of the fact that no objective measures of correctness have ever been applied to check the correctness of these two impressionistic views, it is evident that an acceptance or a rejection of any one of these views, will be a pure arbitrary act.

\subsection{Experimental phonetic data}

An experimental phonetic investigation into the phenomenon of labialization in Sesotho was conducted, ${ }^{6)}$ in order

(i) to gather a minimal corpus of experimentally verified phonetic data about the phenomenon, and

(ii) to determine to which extent the impressionistic phonetic claims of Tucker and of Kunene may be supported, refuted, or complemented by the experimentally obtained data.

On the basis of this experimental investigation the following tentative cinefluorographic, aerodynamic, and acoustic data about the phenomenon of labialization in Sesotho may now be considered:

\subsubsection{Cinefluorographic data}

A cinefluorographic investigation into the articulatory characteristics of labialized segments reveals the following:

1. that significant differences exist between the articulatory configurations of consonants articulated respectively, in $/ a-a /, / a-o /$, and /a-wa/ sequences. Consider the following diagrams depicting the point of tongue-alveolar contact of the segment $/ c^{\prime} /$ in respectively $\mid a-a /$, $\mid a-o /$, and /a-wa/ sequences. 


\section{ग...,}

$(-4)$
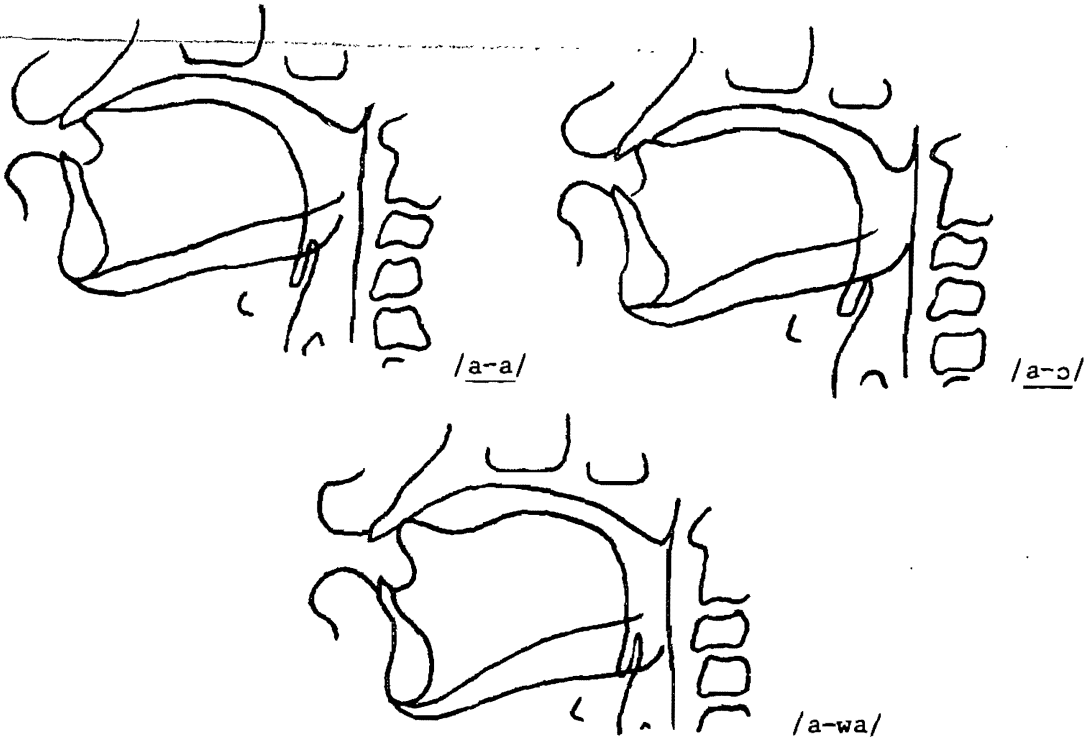

|a-wa/

From this example it follows that

(i) a depression occurs in the anterodorsal area of the body of the tongue just behind the point of occlusion in the /a-wa/ sequence, but not in the $|a-a|$, or in the $/ a-s /$ sequences;

(ii) the body of the tongue is more retracted as a whole in the /a-wa/ sequence than, respectively, in the /a-a/, or $/ a-a /$ sequences;

(iii) at the point of tongue-alveolar contact the mouth exhibits a larger opening in the /awa/ sequence than, respectively, in the $|a-a|$, or $|a-s|$ sequences;

(iv) much more lip protrusion is recorded in the /a-wa/ sequence than, respectively, the $/ a-a /$, or $/ a-y / s^{-}$ quences;

2. that much more overall tongue and lip activity is recorded for consonants articulated in /a-wa/ sequences than for the same consonants articulated, respectively, in $/ a-a /$ and $/ a-s /$ sequences;

3. that varying degrees of anticipation of the lip positions of, respectively, $/ \mathrm{s} /$ and $/ \mathrm{w} /$ segments are recorded prior to the articulation of the consonant preceding these segments. 
These findings to a large extent support the observations of Tucker (1929), and of Kunene (1961) that lip activity is present prior to, and during the articulation of a consonant preceding $/-0 /$ and $/-w /$ segments. The claim, however, of Tucker (1929: 76) that "Labialized consonants, (...), are identical in articulation with the consonass found before back vowels", is totally refuted by these data.

\subsubsection{Aerodynamic data}

An investigation by means of an electro aerometer, into the aerodynamic qualities of labialized segments in Sesotho reveals the following:

1. that coarticulatory air flow phenomena are present during the estimated closure phase of nonlabial consonants in respectively /a-s/, and /a-wa/ sequences, but very seldom in $|a-a|$ sequences;

2. that a specific type of phonetic segment, possibly $[w]$, may be identified in the acoustic signal. Consider the following two examples:

(5) (i)

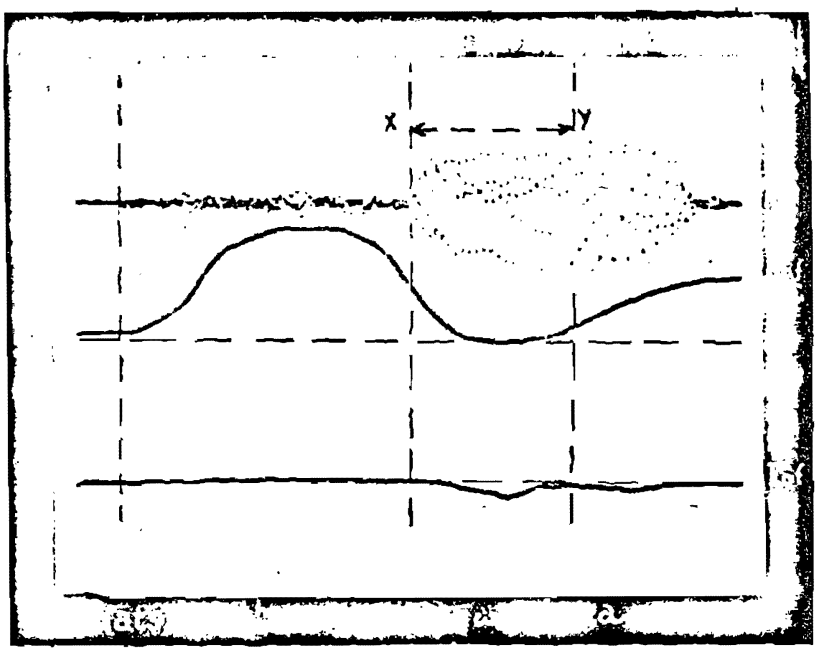


(ii)

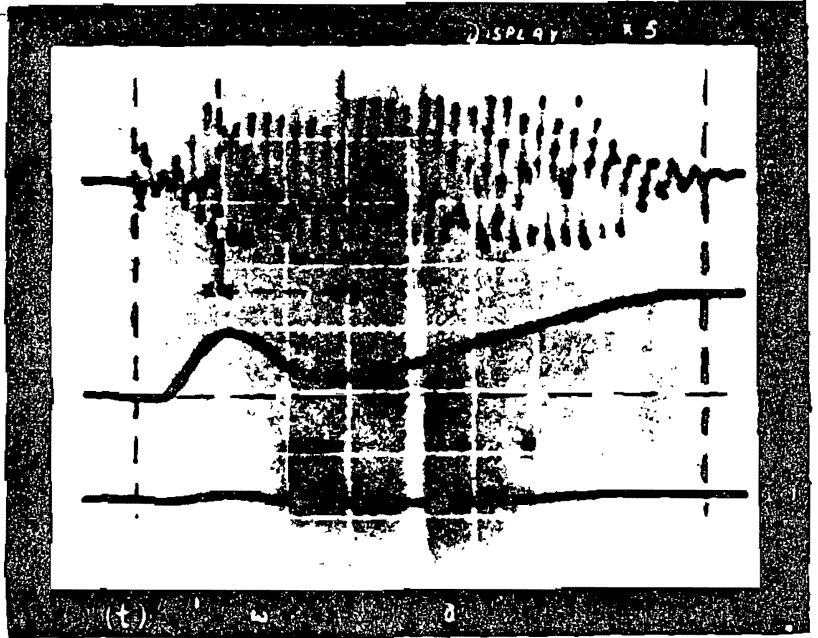

In these two examples Ac denotes the acoustic signal, Eof denotes egressive oral (air) flow, and Iof denotes ingressive oral (air) flow.

The qualititative differences marked $X-Y$, in the sound wave suggest the existence of some kind of element other than the final [a] denoted by the periodic oscillations after $Y$. The periodic oscillations between $X$ - Y may very well be attributed to a phonetic segment [w] preceding the final [a].

3. From ( 5 i, 5 ii) it may further follow that the identified segment [w] follows ejectivization/aspiration. Consider the sharp rise in Eof in both cases: this sharp increase in Eof may be correlated directly with aperiodic oscillations in Ac, which, naturally, represents ejectivization and aspiration respectively (i.e. the section between the discontinued vertical line to the left and $x$ ). Notice that in both instances the $X$ - $Y$ section commences after the Eof had already reached its peak.

The main findings of this investigation seem to refute the impressionistic phonetic claims of Tucker (1929) that

(i) "the $w$ element .... is not a separate succeeding semi-vowel" (1929: 74), and 
(ii) that ejectivization/aspiration 'follows' labialization (points $4,5,6$ in 1.1 ).

On the other hand, it seems to lend support to the observation of Kunene (1961 : 120) that "The interval between the consonant and the following $\underline{w}$ is $(\ldots)$ long enough in Sotho for the sequence to be regarded as a combination."

\subsubsection{Acoustic data}

A spectrographic investigation into the acoustic qualities of labialized segments in Sesotho reveals the following:

1. that the average duration of a /aCwa/ sequence is considerably longer than that of an $/ \mathrm{aCa} /$ or $/ \mathrm{aCo} /$ sequence respectively;

2. that the spectral qualities of, respectively, $/ \mathrm{aCa} /, / \mathrm{aC} /$, and /aCwa/ sequences suggest that a phonetic segment [ $w$ ] may be identified in the /aCwa/ sequence. Consider the following hand painted diagrams of the original spectrograms of /at'a/, /at'o/, and /at'wa/ articulations:

(6 i)

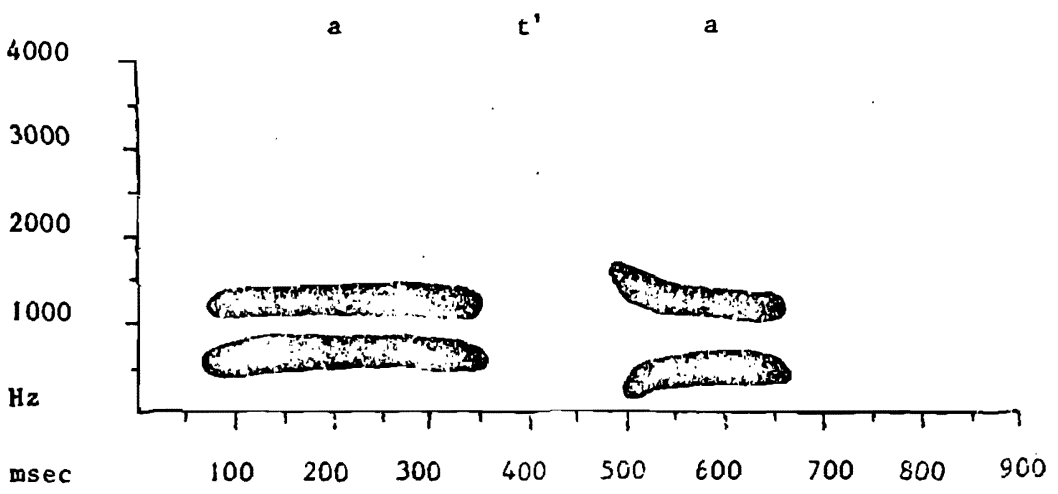



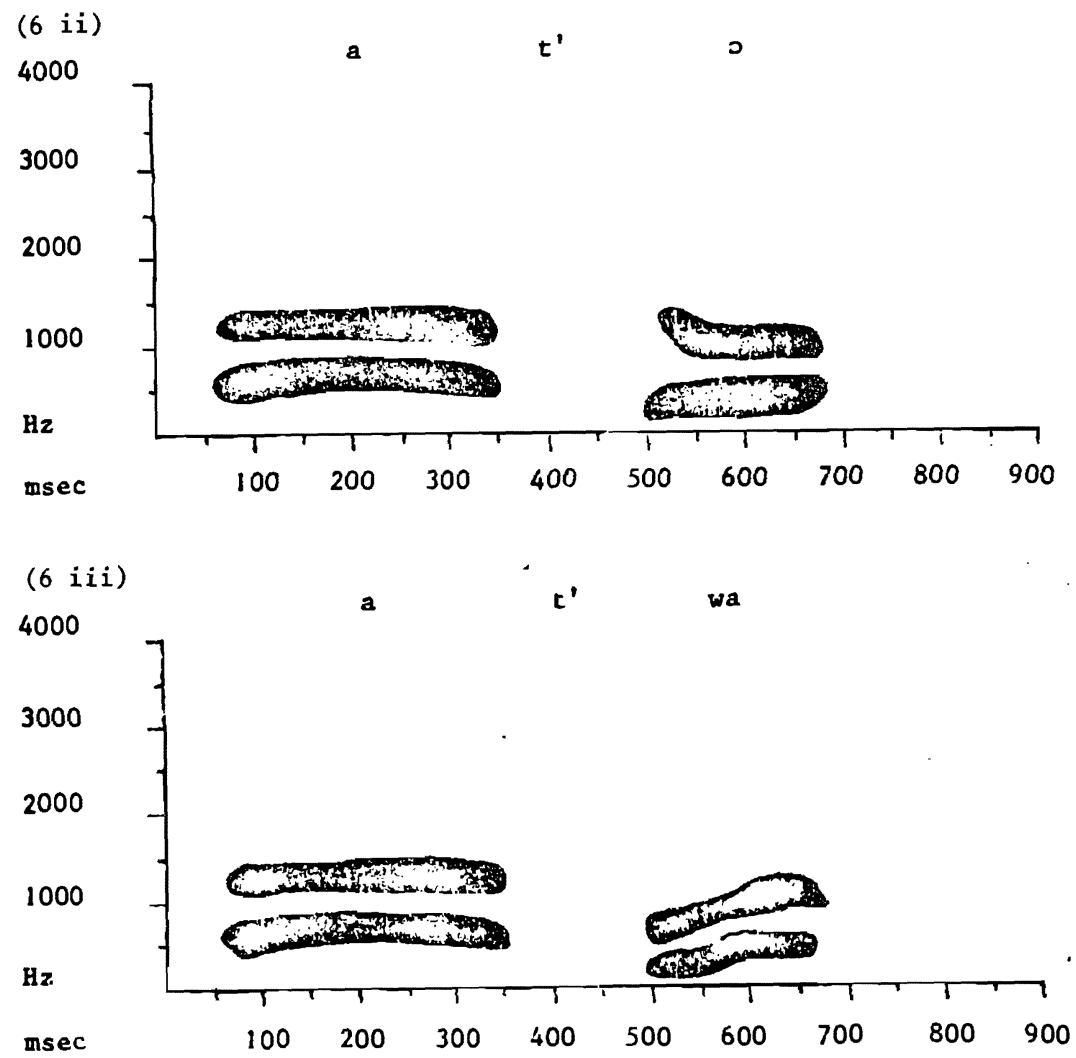

The labiovelar glide [w] is characterized by an initial low intensity of both the first and the second formants, with a distinct transition to the following (vocalic) target area. This transition is indicated by an upward deflection of both formants towards the target area of the following vowel (cf. O'Connor et al. 1957: 301, 302; Lehiste and Peterson 1961: 277). The lowering of $F 1$ and $F 2$ as well as the upward deflection towards the target area of the following vowel is clearly observable in (6 iii), while it is, for instance, not found in (6 i) or (6 ii). 
These observations therefore, seem to refute the claim of Tucker (1929: 74) that "... the w- element (...) is not a separate succeeding semi-vowel." On the other hand, they seem to lend support to the observation of Kunene (1961 : 120) that "the w-element (...) follows the articulation of the labialized consonant."

On the basis of these experimental data it is suggested that two separate phenomena be recognized in Sesotho, i.e. a phenomenon of Rounding, and a phenomenon of Labialization Proper. Rounding pertains solely to the activity of the lips, and is induced by a back rounded vowel following a consonantal segment. In articulating the consonant the liprounding features of the following back vowel are anticipated and imparted on the consonant - such an articulation may phonetically be transcribed as [ $\left.\mathrm{C}^{\circ} \mathrm{o}\right]$. In the case of Labialization Proper the consonant acquires an increased degree of 1 iprounding, as well as varying degrees of tongue and jaw participation. This type of articulation occurs only in an / CwV/ environment, and may be appropriately transcribed as $\left[\mathrm{CW}_{\mathrm{w}}\right] \mathrm{P}^{7)}$

\section{4 "Data" and "Facts"}

Reconsidering now the views of Tucker and Kunene in the light of the experimentally obtained phonetic data, it is clear that very little objective evidence may be presented in support of the views of Tucker. On the other hand, these data seem to support the views of Kunene that

(i) a semivowel $/ \mathrm{w} /$ induces labialization proper, and

(ii) the semivowel $/ \mathrm{w} /$ occurs phonetically as. a separate succeeding segment after the labialized consonant.

In view of the proposed distinction between "data" and "facts" (cf. Botha, in preparation : 82), it may seem reasonable to regard the data of Tucker as "non-facts" and the data of Kunene as "facts". It appears that ".... after careful testing", the data of Kunene, ".... seem(s) to be beyond reasonable doubt", (ibid.); the same, however, can not be said of the data of Tucker.

While the data of Kunene may be considered "correct", it always need to be remembered that not all "correct" data are necessarily linguistically relevant. In this respect, however, it was indifated (cf. section 1), that the linguist may receive some guidance from the phonological theory in terms of 
-which-he-is-operating. -Generative phonological theory requires, for instance, that a phonetic representation should represent or describe a certain perceptual reality (cf. Chomsky and Halle $1968: 25,65,298$ ). The views of Tucker and those of Kunene all seem to meet this requirement, as they are representative of the perceptual judgements of, respectively, a trained phonetician, and a native speaker of the language. Thus, although the views of Tucker and of Kunene may in principle be considered linguistically relevant, only the data of Kunene are considered to be "correct".

Schematically the situation may be presented as (7):

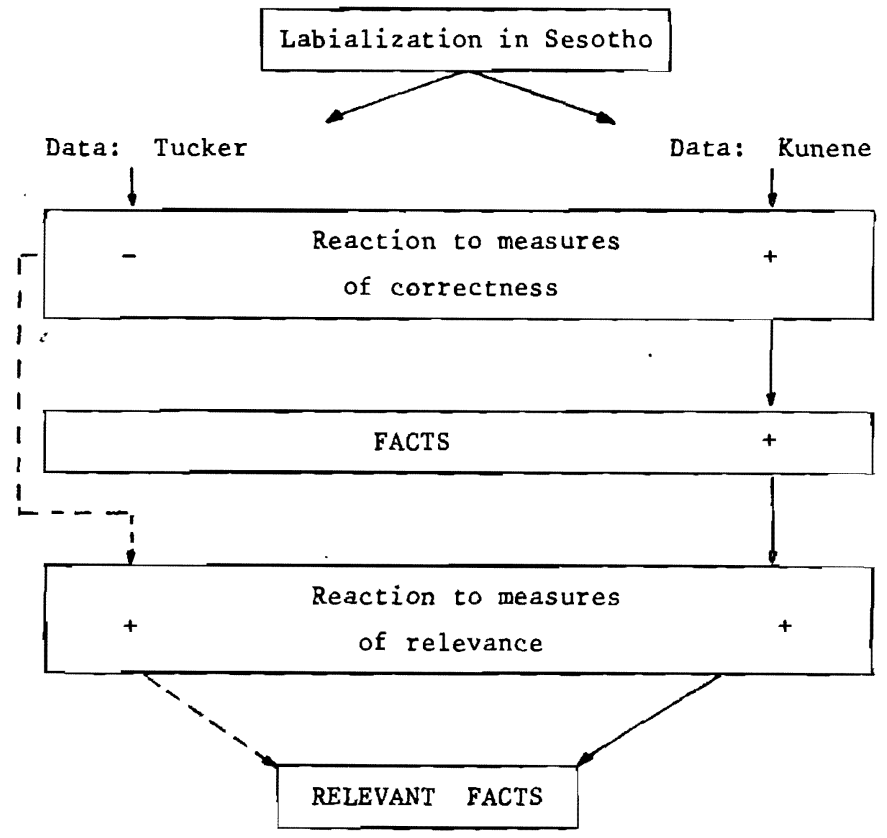

2. Phonological analyses

In this section attention will be given to the consequences of an arbitrary acceptance of respectively, unverified phonetic data (i.e. "non-facts"), and verified phonetic data (i.e. "facts") as a source for phonological analyses. For this purpose, an analysis of Ponelis (1974), which is implicitly based on the views of Tucker will be examined, after which an analysis based on the "facts" of Kunene will be considered. 


\subsection{A phonological analysis based on unverified phonetic data}

In an article entitled "On the dynamics of velarization and labialization: some Bantu evidence", Ponelis (1974) presents, inter alia, an analysis of the process of labialization in Sotho. Although the article is largely concerned with diachronic aspects of these phenomena, it nevertheless makes some specific claims on the synchronic process of labialization in Sotho. These claims will now be examined here critically.

Although Ponelis makes no explicit reference to the source of his data, it is clear that he adheres to the basic views of Tucker in this respect. Consider the following description:

1. ".... in Sotho, (...) all linguals are rounded before sonorants. The labialization is manifested as an extreme rounding affecting a given segment from beginning to end; $c f$. the following Northern Sotho forms where the rounding is signified by a raised $\mathrm{n}$ :

\begin{tabular}{|c|c|c|}
\hline$[$ tšh Kukłud & ţ̌hukudu & 'rhinoceros' \\
\hline [-rwoka] & -roka & 'sew' \\
\hline -1 Woma ] & -loma & 'bite' \\
\hline
\end{tabular}

It seems, however, that the rounding may - and usually does - develop into an offglide", (1974: 40);

2. "The [W] offglide is not by any means a separate glide but a rounded transition to the following non-round vowel, cf. Northern Sotho [-కẉ̨u] -sweu 'white', [-rwala] -rwala 'carry'" (1974:41).

Ponelis (1974 : 39) posits the following rule for "Labialization proper": (8) $\mathrm{C} \rightarrow[+$ round $] /-\left[\begin{array}{l}+ \text { son } \\ + \text { round }\end{array}\right] \quad$ (Labialization : LAB)

The combination of the features [+ son, + round] implies that rounded vowels, as well as the rounded semivowel /w/ may induce labialization. In Sesotho it thus means that the rounded back vowels $/ u /, / u /$, and $/ \mathrm{o} /$, as well as the semivowel /w/ may cause the labialization of a preceding consonantal segment. This, of course, is totally in line with the view of Tucker that "Labialized consonants, ...., are identical in articulation with the consonants found before back vowels" (Tucker 1929: 76).

Ponelis (1974 : 41) also employs a Glide Absorption (GA) rule in his eventual analysis. This rule, however, is not explicitly formulated; he merely states 
"Nothing much need be said about this: the glide is absorbed into the rounding of the labialized segment" (ibid.). The following informal formulation may probably be presented for this rule:

(9) $\quad C w+C w$ (Glide Absorption : GA)

The LAB rule is ordered before the $G A$, and hence the following derivation results (cf. Ponelis $1974: 41$ ):

$$
\begin{array}{llll}
C & w & a & \\
C w & w & a & \text { Labialization } \\
C w & & a & \text { Glide Absorption }
\end{array}
$$

This analysis of Ponelis, however, exhibits serious deficiencies, some of which will be considered below. Specific consideration will now be given to

(i) the form of the input of the derivation,

(ii) the nature of the LAB rule.

The input / Cwa/ to the derivation (10), may be interpreted in two ways: firstly it may be seen as a genuine underlying representation, or secondly, it may be interpreted as an intermediate representation arising from the application of other rules. Consider now the first possibility, i.e. that /Cwa/ is an original underlying representation. ${ }^{9)}$ This possibility, however, must immediately be rejected as no independent evidence can be presented in support of the existence of an underlying segment /w/ in Sotho. Consider

\begin{tabular}{|c|c|c|c|c|c|}
\hline Class 1 & $\mid b+a /$ & $:$ & [wa] & wa & 'of \\
\hline Class 3 & $\mid u+a /$ & : & [wa] & wa & \\
\hline Class 4 & $|i+a|$ & : & {$[j a]$} & ya & \\
\hline Class 9 & $|i+a|$ & : & {$[\mathrm{ja}]$} & ya & \\
\hline
\end{tabular}
the following forms:

(11) (i) The formation of possessive concords:

(ii) The formation of absolute pronouns:

$\begin{array}{lll}\text { 2nd pers. sing. } / u+E+n a /: \text { [wena] wena 'you } \\ \text { Class } 3 & / i+o+n a /: \text { [jona] yona 'it' } \\ \text { Class } 9 & / i+o+n a /: \text { [jona] yona 'it' }\end{array}$

(iii) The formation of diminutives of nouns ending in $|-u|, \mid-\underline{-u}$ or /-a/:

tau 'lion' $/ N+t^{\prime} a^{2} u+a n a /:$ [ $t$ awana] tawana motho 'person' /mu $+t^{h_{u}}+a n a /:$ [muthwana] mothwana leihlo 'eye' /1i + ?iło + ana/ : [1ihizwwana] leihlwana 
From these examples it is clear that [w] may be derived from underlying /u/, $/ 4 /$, or $/ 0 /$ by means of a general gliding rule of the following format:

$$
\left[\begin{array}{c}
+ \text { voc } \\
-1 \text { low } \\
\alpha \text { back }
\end{array}\right] \rightarrow\left[\begin{array}{l}
- \text { voc } \\
- \text { cons } \\
\alpha \text { back }
\end{array}\right] /-\left[\begin{array}{l}
+ \text { voc } \\
- \text { high }
\end{array}\right] \text { (G) }
$$

If, on the other hand, it is accepted that /Cwa/ is an intermediate representation arising from the application of the GL rule to the underlying representation / Cua/, then consider the following consequences:

1. The $L A B$ rule must be extrinsically ordered after the GL rule, as it is suggested that "In Sotho original clusters of lingual consonant and $w$ are converted to $\mathrm{CW}^{\mathrm{W}}$ via labialization." (Ponelis $1974: 41$ ). This ordering is necessary as there is nothing in the structural description of the rule blocking the application of the rule to back vowel environments, or allowing it to be applied only to the semivocalic environment. Hence,

$$
\begin{array}{llll}
\text { C } & \text { u } & \text { a } & \\
\text { C } & w & \text { a } & \text { Gliding } \\
\text { Cw } & \text { w } & \text { a } & \text { Labialization } \\
\text { Cw } & & \text { a } & \text { Glide Absorption }
\end{array}
$$

In such a derivation, however, the relevance of the GL rule becomes highly suspect. It seems as if the GL rule has a function to convert an underlying representation/Cua/, which, as such already meets the structural description of the $L A B$ rule, into another intermediate representation /Cwa/ before the $L A B$ rule may be applied. Immediately after the application of the $L A B$ rule, however, the glide is "absorbed" again into the rounding of the consonant, as it is argued that the segment /w/ does not occur phonetically after a labialized consonant. Clearly, the GL rule is applied here in an unmistakable ad hoc manner.

2. The GA rule has no independent standing. Apart from this one application, it may seriously be doubted whether a GA rule may be independently motivated in Sotho. The sole function of this rule seems to be to convert an alleged phonetically unattested intermediate representation / $\mathrm{W}_{\mathrm{wa}}$ / into an acceptable phonetic output [ $\mathrm{CW}_{\mathrm{W}}$ ]. For this matter then, a glide deletion rule may probably have exactly the same effect. It is indeed difficult to see why Ponelis decides on the name "Glide Absorption" when, in enumerating the factors conditioning "w-Absorption", he states: "... w drops more readily (sooner) when this (cluster initial segment : J.C.R.) is a labial : 
㠃.

Manyika powiza > priza 'giraffe'; Zezuru : mpwara > mpwara 'flint'. In this, the initial form of whsorption, the labial glide is absorbed into the labiality of the cluster initial, hence the name of the rule" (Ponelis 1974 : 38; my emphasis : J.C.R.). On the one hand it is argued that the glide is "dropped" (therefore, in acceptable phonological terms, "deleted"), whilst on the other hand it is claimed to be "absorbed":

3. If no ordering restrictions are imposed on the GL and the LAB rules, and if the $L A B$ rule is retained in its present form (8), it seems possible to argue for at least two further derivations:

Derivation 1

Consider the following derivation in which the LAB rule is applied to an underlying vowel environment:

$$
\begin{array}{lrll}
\text { C } & \text { u a } & \\
\text { Cw } & \text { u a } & \text { Labialization } \\
\text { Cw } & \text { w a } & \text { Gliding } \\
\text { Cw } & \text { a } & \text { Glide Absorption }
\end{array}
$$

The same points of criticism raised against the GL and the GA rules in (13) seem applicable here: their function and motivation are highly suspect.

\section{Derivation 2}

Consider now a derivation in which neither the GL nor the GA rule has any function whatsoever:

$$
\begin{aligned}
& \text { C u a } \\
& \text { Cw u a Labialization } \\
& \text { cw a Vowel Deletion }
\end{aligned}
$$

\begin{tabular}{|c|c|c|c|c|c|}
\hline Class 2 & $/ b a+a /$ & $:$ & [ba] & ba & 'of \\
\hline Class 5 & $/ 1 i+a /$ & : & [ $1 \mathrm{a}]$ & la & $"$ \\
\hline ass 7 & $\mid s i+a /$ & : & [sa] & sa & \\
\hline
\end{tabular}

This rather short derivation contains a Vowel Deletion rule for which ample independent support may be obtained in Sesotho. Consider the following forms:

(i) The formation of possessive concords 
(ii) The formation of quantitative pronouns

\begin{tabular}{|c|c|c|c|c|c|}
\hline class 2 & $/ b a+o q \varepsilon /$ & $:$ & 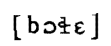 & bohle & 'all, everyone' \\
\hline Class & $\mid l_{i}+\Delta \Varangle \varepsilon /$ & : & [ lЈqع] & lohle & 'the whole \\
\hline lass & $\left|s_{i}+o t \varepsilon\right|$ & : & [sつt $\varepsilon]$ & sohle & 'the whole' \\
\hline
\end{tabular}

(iii) The formation of diminutives

thaba 'mountain' $/ N+t^{\text {haba }}+$ anal : [thabana] thabana

metsi 'water' /ma + ?its'i+ana/: [mets'ana] metsana

From these examples it is clear that, in the case of a juxtaposition of two vowels, the first of the two vowels is deleted in order to convert a violated syllable structure /CVV/ into a preferred syllable structure of /CV/ in Sotho. This rule of Vowel Deletion may be formalized as

$$
\mathrm{V} \rightarrow \phi / \mathrm{C}-\mathrm{T} \cdot \mathrm{V} \quad \text { (Vowel Deletion : VD) }
$$

It thus seems to be possible to account for the phenomenon of labialization in Sesotho without making any reference to the labiovelar glide / $/ \mathrm{w}$ in any way.

After having discussed the form of the input in (10), reference will now be made to the nature of the $L A B$ rule as proposed by Ponelis. This rule (8) states that a consonant may be labialized by a following back vowel, or by the semivowel /w/. Reconsider now the following description of Ponelis (1974 : 40): "... all linguals are rounded before rounded sonorants. The labialization is manifested as an extreme rounding affecting a given segment from beginning to end; $c f$. the following Northern Sotho forms where the rounding is signified by a raised $x$ :

$\begin{array}{lll}\text { [tšhthukłudYu] } & \text { tšhukudu } & \text { 'rhinoceros' } \\ \text { [-ryoka] } & \text {-roka } & \text { 'sew' } \\ \text { [-1Yoma] } & \text {-loma } & \text { 'bite' }\end{array}$

"It seems, however, that the rounding may - and usually does - develop into an offglide. Hence:

(18)

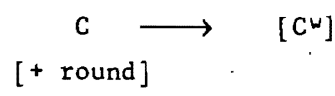

Presented in the form of a derivation, Ponelis seems to suggest the following:

$$
\begin{array}{ll}
\text { Co } & \\
\text { Cho } & \text { Labialization } \\
\text { CWo } & \text { Offglide }
\end{array}
$$


The format of the offglide (OG) "rule" suggests that it should be interpreted as a low level phonetic rule (cf. Chomsky and Halle $1968: 65,3 / 2$ ), rather than as a phonological rule proper. The fundamental question, however, to be answered here is, why does Ponelis make a distinction between the outputs of the $L A B$ rule when it is applied respectively, in a semivocalic environment, or in a back vowel environment? Reconsider derivations (10) and (19), presented here as (20 i) and (20 ii) respectively:

$\begin{array}{lllllll} & C & w & a & C & 0 & \\ L A B & C W & w & a & C & 0 & L A B \\ G A & C W & a & C w & 0 & O G\end{array}$

Clearly, a phonological rule assigning the feature value [+ round] to a given segment, cannot have two different outputs, viz. / $\mathrm{CH} /$ in one case and / $\mathrm{Cw} / \mathrm{in}$ the other. The impression is created by (20 ii) that the labialized consonant $/ \mathrm{CH} /$ just isn't "labial" enough and that it requires a phonetic rule to create an acceptable and "correct" phonetic output [ $\left.\mathrm{CW}_{0}\right]$. On the other hand, it seems as if the labialized consonant / CW/ in (i) may be "labial" enough, but that a GA rule is necessary to discard the phonetically unattested segment /w/. The question may now be asked whether Ponelis is not forced into this untenable situation through his acceptance of the "quasi-fact" that "The labialized consonant is in short precisely the consonant one hears before a back vowel" (Tucker $1929: 74)$ ?

Because of this acceptance, it is necessary to formulate the LAB rule as such, that it allows labialization to take place before a semivowe $1 / \mathrm{w} /$, as well as before a rounded back vowel. In other words, the LAB rule (8) actually comprises two rules, viz.:

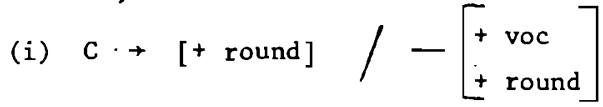

$$
\begin{aligned}
& \text { (ii) } C \rightarrow[+ \text { round }] /-\left[\begin{array}{l}
- \text { voc } \\
- \text { cons } \\
+ \text { round }
\end{array}\right]
\end{aligned}
$$

It is, however, an open question whether a rule such as (21 i) is phonologically relevant in Sotho, and consequently, whether it is justified to accept this rule as a phonological rule proper. It is generally known that during, or even prior to the articulation of a specific phonetic segment the active articulatory organs, and in some cases even the inactive articulatory organs, tend to anticipate the articulation of a following segment (cf. Fromkin 1970: 37 ). 
This phenomenon is commonly referred to as anticipatory co-articulation (cf. Ladefoged 1975: 49; Daniloff and Hanmarberg 1973:239). This "overlapping of adjacent articulations" (Ladefoged $1975: 48$ ), may have the effect that a consonantal segment acquires an increasing measure of palatalness if it is articulated, respectively, before the vowel segments $/ \varepsilon, e, i, i /$ in that order. Likewise, a consonant may become more rounded if it is articulated before, respectively, the vowels / $, o, u, u /$ in that order. This phenomenon, however, may be viewed as a phonetic phenomenon which, as such is "... not part of the phonologies of individual languages, but rather belong to the realm of universal phonetics" (Hyman 1975: 171). "Al1 such 'intrinsic' or 'coarticulated allophones' (...) are of virtually no importance to phonology, since they are not language specific" (Campbel1 1974:61 n. 11). It is to be doubted whether the rounding of a consonant before a back vowel in Sesotho is of any phonological importance whatsoever, and it is suggested that it be viewed mere$1 y$ as a coarticulatory phenomenon. Experimental phonetic investigations in any case indicate (cf. 1.3.1, 1.3.2, 1.3.3) that the articulatory differences between, for instance, -na "(to) rain" [na] and -nwa "(to) drink" [nwwa] are more than only differences in liprounding.

The phenomenon, described by Ponelis (1974:40), and represented in (18), (19), and (20 ii) seems to be a phonetic phenomenon rather than a phonological phenomenon, - hence the phonologically unmotivated rules in his description. Returning to the format of the LAB rule (8), (21 i, ii): it seems clear that, as a phonological rule in Sesotho, the LAB rule should be constrained to the effect that it is only applicable to semivocalic environments. This may be accomplished by omitting $(21 \mathrm{i})$ as a phonological rule proper in Sesotho, and retaining ( $21 \mathrm{ii}$ ), which in any case, will be in line with the following experimentally supported phonetic view of the native speaker Kunene (1961 : 118): "When a consonant other than a labial consonant is immediately followed by the labio-velar semivowel $\underline{w}$, the latter imparts labial characteristics, in the form of lip-rounding, to the preceding consonant."

From the previous discussion it has become clear that, in order to account for unverified phonetic data, the linguist tends to use unmotivated, ad hoc, and even phonetically less plausible phonological rules in his analysis.

\subsection{A phonological analysis based on "facts"}

In this section an analysis will be proposed on the basis of the "facts" of Kunene on the phenomenon of labialization in Sesotho. Although the proposed 
analysis may at first appear to be relatively simple, it will be shown, however, that certain readjustments to the formulation of the phonological rules are necessary to express certain generalizations.

Consider now the following forms:

(i) Diminutives with /-ana/:

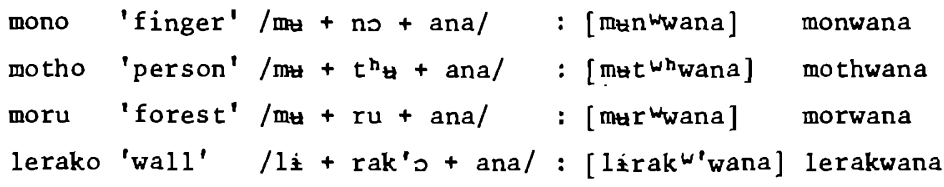

(ii) Passives

-rata '(to)love' /rat' $+u+a /{ }^{11)}:$ [ratw'wa] -ratwa 'be loved'

-reka '(to)buy'. /rek+u+a/ : [rekw'wa] -rekwa 'be bought' -apara '(to)dress' /ap'ar + u+ a/ : [ap'arwwa] -aparwa 'be dressed'

Given now an independently motivated GL rule (12), reformulated here as (23)

$$
\left[\begin{array}{l}
+ \text { voc } \\
- \text { low } \\
\alpha \text { back }
\end{array}\right] \rightarrow\left[\begin{array}{l}
- \text { voc } \\
- \text { cons } \\
\alpha \text { back }
\end{array}\right] /\left[\begin{array}{l}
+ \text { voc } \\
- \text { high }
\end{array}\right] \quad \text { (Gliding : GL) }
$$

and, given further a readjusted $L A B$ rule (8), reformulated here as (24)

$$
c \rightarrow[+ \text { round }] /\left[\begin{array}{l}
- \text { voc } \\
- \text { cons } \\
+ \text { round }
\end{array}\right] \quad \text { (Labialization : LAB 2), }
$$

the following derivation may now be presented (cf. 22 i, ii):

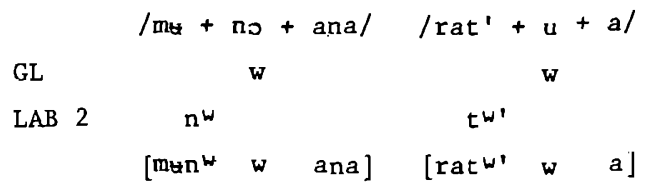

From the format of the two rules (23) and (24), it is clear that they stand in a feeding relationship in that the GL rule creates the environment for the $L A B$ rule to be applied. The analysis therefore seems to be quite simple: there is no necessity for GA, VD, or OG rules, nor any uncertainty as to the order of the application of the GL and the LAB 2 rules. 
A serious problem, however, still remains with respect to the feature "round", denoting labialization. On the basis of the experimental data, it was suggested in the previous section that a distinction should be made between "rounded" consonants which are, phonologically speaking, irrelevant, and "labialized" consonants which are of phonological importance in Sesotho. It was indicated that a labialized consonant acquires more than only liprounding in the process of labialization; this, however, is not reflected in the LAB 2 rule. While extraneous "scape-goat" features ${ }^{12)}$ [- voc, - cons] are used in the LAB 2 rule to express this difference, the basic point is missed, namely, that it is actually the feature "round" that is in need of redefinement, or even of replacement.

The view Chomsky and Halle (1968: 310) take on labial and labialized articulations, is well known in phonological circles. In short, they assign the feature values [+ ant, - cor] to true labial articulations, and the feature value [+ round] to labialized articulations. This treatment, however, has turned out to be deficient in at least two ways. It fails to explicitly express possible relationships existing between

(i) true labials such as [p,b, m], which are [+ ant, - cor, -round], and labialized segments such as $\left[t w, 1^{w}, k^{w}\right]$, which are $[+$ round];

(ii) true labials which are [- round], and rounded vowels which are [+ round]. These deficiencies have been subjected to incisive criticism by among others, Hyman (1975 : 53), Reighard (1972 : 533-), Campbe11 (1974 : 52-), and Ladefoged and Vennemann (1971:14). In the following discussion examples will be presented to demonstrate just how certain generalizations in Sesotho are obscured through the use of inter alia, the feature "round".

Consider the following passive forms:

$$
\begin{aligned}
& \text { (i) -rata 'love' - /rat' + u + a/ : [ratw'wa] -ratwa } \\
& \text { (ii) -bopa 'mould' - /bup' + u + a/ : [bupjw'wa] }{ }^{13)} \text {-bopjwa } \\
& \text { [butsw'wa] -botjwa } \\
& \text { (iii) -roba 'break' - /rob }+u+a /:\left[r o b 3 w_{w a}\right] \text {-robjwa } \\
& \text { [ } \left.\operatorname{rod}_{3} w_{w a}\right] \quad-r o j w a \\
& \text { (iv) -roma 'send' }-/ r o m+u+a /:[r>0 \text { wa] -rongwa }
\end{aligned}
$$

The underlying representations (26 $i$ - iv) al1 meet the structural description of the GL rule (23); an application of this rule will yield the following intermediate stage in a derivation: 
(27)

$\frac{\text { (i) }}{\text { rat' } u \text { a }}$ bup'u

GL w (iii)

rob u a

$\mathbf{w}$ (iv)

rom u a

$\mathbf{W}$

If the final phonetic outputs of $(26 i-i v)$ are taken into account, it appears that

(i) non labial consonants become labialized / t'w/: [t''w],

(ii) labial consonants become

(a) labio-palatalized / $/ p^{\prime} w /:\left[p \int^{\prime} w\right] /\left[t \int^{\prime} w\right]$ $/ b_{w} /:\left[b_{3} w_{w}\right] /\left[d_{3} w_{w}\right]$

(b) labio-velarized /nww/ : [ $\mathrm{gww}]$

In Sesotho labial segments do not labialize in a typical labialization environment, they tend to become labialized (labio-)palatals or labialized velars. Doke and Mofokeng (1967: 28) ascribe this phenomenon to "......... the incompatibility of labial consonants with the semi-vowel w."

From these observations the following inferences may be made:

1. A segment of which the primary articulation does not involve the lips, takes on the labial features of the following semivowel (cf. 26, i).

2. A segment of which the primary articulation does involve the lips, as sumes

(i) the tongue height features of the following semivowel, if this. segment is non-nasal (cf. 26, ii, iii), or

(ii) the backness of the following semivowel, if this segment is a nasal (cf. 26, iii).

The representation

(28)

$$
\left[\begin{array}{l}
+ \text { ant } \\
- \text { cor } \\
- \text { round } \\
\hdashline
\end{array}\right]+\left[\begin{array}{l}
- \text { voc } \\
- \text { cons } \\
\left.-\begin{array}{l}
\text { ant } \\
- \text { cor } \\
+ \text { round } \\
+ \text { high } \\
+ \text { back } \\
-\cdots
\end{array}\right]
\end{array}\right]
$$


however, completely fails to reflect the fact that it is the incompatibility of the labiality of the consonant with the labiality of the semivowel that probably gives rise to the palatalization on velarization of the initial consonant. The feature compositions [ + and, - cor, - round], and [- ant, -cor, + round] are insufficient to express the above mentioned generalization in a clear and transparent fashion. From this discussion it is clear that a feature referring to labiality as such, may probably solve this problem.

On the basis of experimentally obtained phonetic data, 14) is now proposed with the following content:
A sound has a positive value for the feature "labial" if it is produced with a distinct approximation of the lower lip to either the upper lip or the upper teeth. A depression in the anterodorsal area of the body of the tongue or a slight retraction of the back of the tongue may co-occur together with varying degrees of lipprotrusion.

In terms of the feature "labial" the following classes of speech sounds may be distinguished in Sesotho.

(30)

$\frac{[+ \text { labial }]}{\text { true labials }}$
glide $w$
secondary labialized consonants

$\underline{[-1 \mathrm{abial}]}$

nonlabial consonants

all vowels

In terms of this distinction, the feature compositions of the segments in the intermediate stage (27) are, respectively,

(i)

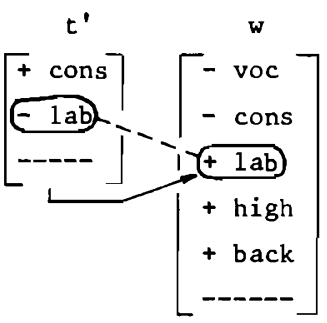

(ii)

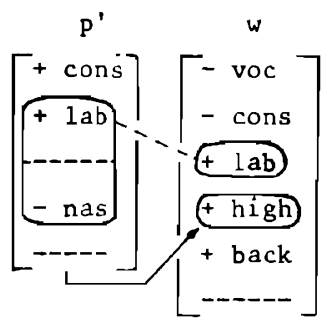

(iii)

m

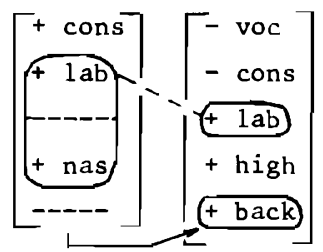

From this representation it clearly follows that 
(i) a nonlabial segment assumes the labiality of the semivowel,

(ii) a non-nasal segment assumes. the tongue height of the semivowel,

(iii) a nasal labial segment assumes the backness of the semivowel.

The following rule of Labialization Proper (LABP) is proposed for Sesotho:

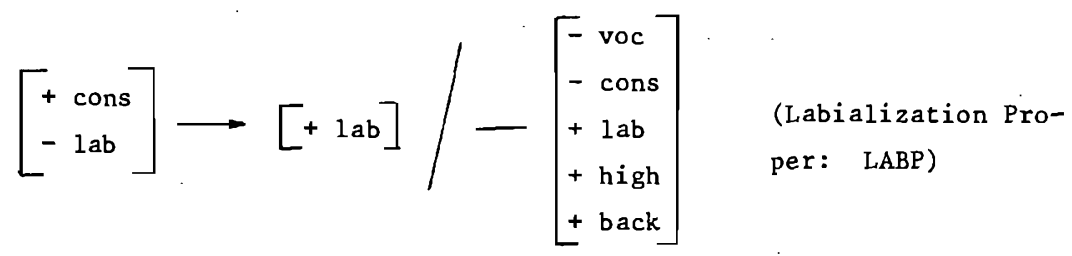

As this rule conceivably follows the GL rule, the following derivation may be presented:

$$
\begin{aligned}
& \text { /C u a/ } \\
& \text { GL } C \text { w a } \\
& \text { LABP CW w a } \\
& \text { [Cw w a] }
\end{aligned}
$$

In conclusion, it appears as if a phonological analysis based on verified phonetic data, i.e. on "facts", does not encounter the same problems as an analysis based on unverified data. In any case, there are no ad hoc rules present and furthermore, both rules employed are phonologically motivated and phonetically verified.

\section{Conclusion}

From the foregoing discussion one point clearly emerged, i.e. that much more attention should be given by linguists to the verification of their primary data. It was shown that a phonological analysis based on unverified phonetic data tends to accommodate ad hoc, and unmotivated phonological rules. To a certain extent this finding does not come as any surprise, after all, how can a. Iinguist expect to account for a set of data in a correct and credible manner, if the correctness of the data as such is not beyond any doubt? A phonological analysis based on verified data, on the other hand, seems to account for the data in a relatively simple and straightforward way. The necessity to distinguish between mere "data" and "facts" in a corpus of linguistic data cannot be overemphasized. It is clear that, along with other 
disciplines, ${ }^{16)}$ experimental phonetics may play an important role in establishing the "facts" in a corpus of phonetic data. Experimental phonetics may, furthermore, provide the means in terms of which new phonetic facts of a specific phenomenon may be revealed.

The question may duly be asked whether the different phonological analyses so often found for a specific phenomenon, are not merely the consequences. of a corpus irrelevant, incomplete, and unverified phonetic data? 


\section{FOOTNOTES}

1. This paper is a revised and extended version of a paper read at the annual congress of the Linguistic Society of South Africa in Pretoria during July 1978. As such, it furthermore contains preliminary results of an ongoing study on phonetical and phonological aspects of the phenomenon of labialization in Sesotho.

2. Sesotho is a Bantu language belonging to the Sotho group of Bantu languages of South Africa (cf. Tucker $1929: 9 \mathrm{ff.}$ ); it is often referred to as Southern Sotho. The indigenous name, Sesotho, as used by Tucker is retained in this paper. When reference is made to "Sotho", it refers to the group of languages.

3. The Afrikaans version of this work is available as Generatiewe Taalondersoek: 'n sistematiese inleiding (1978).

4. See also Dretske-(1974: 35) in this respect.

5. Cf. Doke and Mofokeng (1967: 33); Cole (1955: 34 n. 1); Van Wyk (1977: 136); Ziervogel (1967: 263, 290, 318).

6. Cf. Roux (in preparation): Labialization in Sesotho: The role of phonetic data in phonological analyses.

7. Cf. section 2.2 .

8. It is remarkable that, while Ponelis seems to be concerned with phonetic detail, cf. his distinction between $\left[\begin{array}{l}W \\ \Lambda\end{array}\right]$ and $[W]$, possibly denoting degrees of labialization, he nevertheless omits basic detail in these phonetic transcriptions. For one thing, he does not indicate the ejectiveness of, for instance $/ k^{\prime} /$, in ţ̧hukudu or in -roka, nor does he express himself on the relationship between ejectiveness and labialization. Furthermore, he uses orthographic symbols and even hyphens in these transcriptions, cf. his use of [t $\mathrm{Yh}$ ] and [ $\mathbf{\zeta}$ ] respectively, for $[t S]$ and $[S]$, and also the forms $\left[-Y^{w}\right],[-1 w]$, $\left[-r^{w}\right]$.

9. Ponelis obviously does not suggest this (cf. Ponelis $1974: 39,49$ ), although the derivation as such may imply it. 
10. This rule is naturally in need of refinement as /wi/ combinations also occur phonetically in Sotho.

11. No lengthy discussion is given here for postulating underlying/u/ for the Passive; consider, however, some alternative forms in which this /u/ appears phonetically: moratuwa 'one who is loved' [murat'uwa]; morutuwa 'student' [murut'uwa].

12. Cf. Schourup (1973: 30) for his exposition of "scape-goat" features.

13. The labialized labio-palatal forms [p $\int^{\prime \prime w}$; b $3^{w w}$ ] may, in view of, inter alia, their limited distribution in Sotho be viewed as exceptional forms - see also note 6 , koux (in preparation).

14. Cf. Roux (1976) and Roux (in preparation); see also 1.3.1, 1.3.2, 1.3 .3 of this paper.

15. The forms ( $31 \mathrm{ii}, \mathrm{iii}$ ) may be accounted for by normal rules of palatalization, and labialization respectively.

16. Cf. Ohala (1974: 268). 


\section{REFERENCES}

Botha, R.P.

1971

Botha, R.P.

(in preparation)

Campbe11, L. 1974
: Methodological Aspects of Transformational Generative Phonology. Mouton.

: The Conduct of Linguistic Inquiry.

: "Phonological features: Problems and proposals" in Language $50: 52-65$.

Chomsky, N. \& M. Halle: The Sound Pattern of English. Harper \& Row. 1968

Cole, D.T. : An Introduction to Tswana Grammar. Longmans. 1955

Daniloff, R. \& R. Hammarberg : "On defining coarticulation" Journal of 1973 Phonetics $1: 239-248$.

Doke, C.M. \& S.M. Mofokeng : Textbook of Southern Sotho Grammar. Long1967 mans.

Dretske, F.I. 1974

Fromkin, V.A. 1970

Garnes, S. 1973

Garnes, S. 1974

Hyman, L. 1961

Kunene, D.P. 1961
: "Explanation in Linguistics" in Explaining Linguistic Phenomena, Ed. D. Cohen, John Wiley and Sons.

: "The Concept of 'Naturalness' in a universal phonetic theory" in Glossa 4.1 .

: "Phonetic evidence supporting a phonological analysis" in Journal of Phonetics $1: 273-283$.

: "Suprasegmental Aspects of Icelandic Vowe 1 Qua1ity" in Working Papers in Linguistics 17 : 144 159.

: Phonology - Theory and Analysis. Holt, Rinehart \& Winston.

: The Sound System of Southern Sotho. Ph.D. University of Cape Town. 
Ladefoged, P. 1960

Ladefoged, P. 1975
: "The value of phonetic statements" in Language $\underline{36}, 3: 387-396$.

: A Course in Phonetics. Harcourt Brace Jovanovich, Inc.

Lehiste, I. \& G.E. Peterson : "Transitions, Glides and Diphthongs" in 1961 Journal of the Acoustic Society of America 33.3 : $268-277$.

O'Connor, J.D. et al. : "Acoustic Cues for the perception of initial 1957 $/ w, j, r, 1 /$ in English" in Acoustic Phonetics, Ed. D.B. Fry (1976) Cambridge University Press.

O'Hala, J.J. 1974

Roux, J.C.

1976

Schourup, L. 1973

Tucker, A.N. 1929

Van Wyk, E.B: 1977

Ziervogel, D. et al. : Handboek vir die Spraakklanke en Klankveranderings 1967

: "Phonetic Explanation in Phonology" in Papers from the Parasession on Natural Phonology. Chicago Linguistic Society.

: "n Kenmerk 'labiaal': motivering vanuit SuidSotho" in Taalfasette $20.2: 38-50$.

: "Where binarity fails" in Working Papers in Linguistics 14.

: The Comparative Phonetics of the Suto-Chuana group of Bantu Languages. Longmans, Green \& Co.

: Praktiese Fonetiek vir Taalstudente. Butterworths. in die Bantoetale van Suid-Afrika. Unisa. 